\title{
Corrigendum: Wafer-scale two-dimensional semiconductors from printed oxide skin of liquid metals
}

Benjamin J. Carey, Jian Zhen Ou, Rhiannon M. Clark, Kyle J. Berean, Ali Zavabeti, Anthony S.R. Chesman, Salvy P. Russo, Desmond W.M. Lau, Zai-Quan Xu, Qiaoliang Bao, Omid Kavehei, Brant C. Gibson, Michael D. Dickey, Richard B. Kaner, Torben Daeneke \& Kourosh Kalantar-Zadeh

Nature Communications 8:14482 doi: 10.1038/ncomms14482; published 17 Feb 2017; Updated 22 Mar 2017

The original version of this Article contained a typographical error in the spelling of the author Omid Kavehei, which was incorrectly given as Omid Kevehei. This has now been corrected in both the PDF and HTML versions of the Article.

\footnotetext{
(c) (i) This work is licensed under a Creative Commons Attribution 4.0 International License. The images or other third party material in this article are included in the article's Creative Commons license, unless indicated otherwise in the credit line; if the material is not included under the Creative Commons license, users will need to obtain permission from the license holder to reproduce the material. To view a copy of this license, visit http://creativecommons.org/licenses/by/4.0/

(C) The Author(s) 2017
} 